\title{
Association between Fetal Gender and the Labor Curve at Term Pregnancy
}

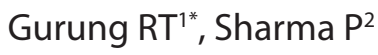 \\ ${ }^{1}$ Lecturer, Department of Obstetrics \& Gynecology, ${ }^{2}$ Lecturer, Department of Radiology, \\ Gandaki Medical College \& Teaching Hospital, Pokhara, Nepal
}

\author{
Keywords \\ Fetal gender, First stage of labor, \\ Labor Curve \\ Corresponding author \\ *Dr. Rubina Tamrakar Gurung, Lecturer \\ Department of Obstetrics \& Gynecology \\ Gandaki Medical College \& \\ TeachingHospital, Pokhara, Nepal \\ Email: tamrakarrubina@yahoo.com.hk
}

\begin{abstract}
Introduction: Animal and pathologic models have provided evidence for a fetal influence on the labor process; however, the potential impact of fetal gender on the labor curve has gone largely unstudied.

Objectives: To determine the association between fetal gender and first stage labor curve at term.

Methods: This was a retrospective study. There were 330 patients enrolled in this study, who gave birth from January 2011 to December 2012 by reviewing the charts. A total of 500 charts were reviewed.

Results: There were three hundred thirty (330) patients, out of which a total of 179 (54.2\%) patients gave birth to males and 151 (45.8\%) gave birth to females. Women who had a male fetus had a longer first stage of labor than women who carried a female fetus. The difference in the birth weight of the infants is statistically significant, male newborns were heavier at birth than female newborns.
\end{abstract}

Conclusions: Term labor in the first stage was found to be slower in women who carried a male fetus compared with those with female fetus which is not statistically significant.

\section{INTRODUCTION}

A scientific approach was begun by Friedman (1954), who described a characteristic sigmoid pattern for labor by graphing cervical dilatation against time. This graphic approach based on statistical observations, changed labor management. Friedman developed the concept of three functional divisions of labor to describe the physiological objectives of each division. During the preparatory division, although the cervix starts to dilates, its connective tissue components change considerably. The pelvic division commences with the deceleration phase of cervical dilatation. The classic mechanisms of labor that involve the cardinal fetal movements of the cephalic presentation-engagement, flexion, descent, internal rotation, extension, and external rotation-take place principally during the pelvic division. In actual practice, however, the onset of the pelvic division is seldom clearly identifiable ${ }^{1}$.
Active labor that is uterine contractions, that brings about progressive cervical dilatation and delivery. Clinically, phase 3 is customarily divided into the three stages of labor ${ }^{2}$

1. The first stage begins when widely spaced uterine contractions of sufficient frequency, intensity, and duration are attained to bring about cervical thinning, termed effacement. This labor stage ends when the cervix is fully dilated, about $10 \mathrm{~cm}$, to allow passage of the fetal head. The first stage of labor, therefore, is the stage of cervical effacement and dilatation.

2. The second stage begins when cervical dilatation is complete, and ends with delivery.

3. The third stage begins immediately after delivery of the fetus and ends with the delivery of the placenta.

Male fetal gender has been identified as a risk factor for 
cesarean delivery ${ }^{3-5}$. This finding has been interpreted as a surrogate for fetal size because male fetuses tend to be larger on average compared with female fetuses. Animal and pathologic models have provided evidence for a fetal influence on the labor process ${ }^{6}$; however, the potential impact of fetal gender on the labor curve has gone largely unstudied.

Fetal gender is independently associated with adverse pregnancy outcome. Boys have higher rates of fetal and neonatal mortality and are more vulnerable to longterm neurological and motor impairments after preterm birth $^{7-10}$. On average, a lower gestational age is observed among males compared with female babies. It has been suggested that a preterm delivery may be induced by fetal gender ${ }^{11}$.These workers reported an excess of males among preterm babies, in agreement with previous findings ${ }^{12}$, suggesting that male fetal gender, hormonally involved in the control of labor onset, might be responsible for the shortened duration of pregnancy. Possible determinants of the variation in the male to female ratio with pregnancy duration have been extensively discussed. In particular, a U-shaped variation has been suggested, which could be related to time of fertilization in the cycle $e^{13-14}$.

\section{METHODS}

This was a retrospective study. There were 330 patients enrolled in this study who gave birth at the Our Lady of Fatima University Medical Center from January 2011 to December 2012, by reviewing the charts. The researcher extracted detailed information on maternal sociodemographic, obstetric, and gynecologic history, medical and surgical history, prenatal history, antepartum records, and labor and delivery records. The labor and delivery records include labor type, dilation and station, length of labor stages, mode of delivery. Cervical dilation was documented in centimeters that ranged from $0-10 \mathrm{~cm}$. Gender was defined as the gender assignment made by the pediatrician at delivery.

A total of 500 charts were evaluated using the inclusion criteria and 330 deliveries were included for this analysis. 170 patients were excluded because they were found to have undergone repeat cesarean section, had malpresentation, dystosia, non-reassuring fetal heart pattern, or they were preterm deliveries. Inclusion criteria were women whose gestational age was more than 37 weeks and 0 days at admission to labor and delivery, if they carried a singleton pregnancy in vertex presentation and the exclusion criteria were women who delivered preterm, had fetuses with congenital anomalies, or delivered by cesarean before complete dilation. Statistical tools were chi square, fisher exact test, mean and standard deviation, Yates corrected test for the probability values.

\section{RESULTS}

There were three hundred thirty (330) patients enrolled in this study who gave birth at the Our Lady of Fatima University Medical Center from January 2011 to December 2012. A total of 179 (54.2\%) patients gave birth to males and 151 (45.8\%) patients gave birth to females. Women who carried a male fetus were similar, on average, to women who carried a female fetus with respect to maternal age, gravidity, labor type, and rates of cesarean delivery (Table 1). No significant difference was seen with regard to labor, rupture of membrane at admission, mode of delivery, hypertension at pregnancy and gestational diabetes mellitus.

The difference in the birth weight of the infants is statistically significant, male newborns are heavier at birth than female newborns.

Table 1: Characteristics of women who carried a male fetus compared with women with a female fetus

\begin{tabular}{lccc}
\hline \multicolumn{1}{c}{ Variables } & $\begin{array}{c}\text { Males } \\
\text { (n=179) }\end{array}$ & $\begin{array}{c}\text { Females } \\
(\mathbf{n = 1 5 1})\end{array}$ & P value \\
\hline Maternal age (in years) & $27.4 \pm 5.5$ & $27.5 \pm 5.8$ & 0.8979 \\
Gravidity & $2 \pm 1$ & $2 \pm 1$ & 0.6389 \\
Nulliparous (\%) & $46.9 \%$ & $50.3 \%$ & 0.5 \\
& & & \\
Labor (\%) & $5 \%$ & $2 \%$ & 0.5 \\
Induction & $50.8 \%$ & $53.6 \%$ & 0.5 \\
$\quad$ Augmentation & $44.1 \%$ & $44.4 \%$ & 0.5 \\
$\quad$ Spontaneous & $4.5 \%$ & $5.3 \%$ & 0.5 \\
Rupture of membranes at & & & \\
admission (\%) & & & \\
Mode of delivery (\%) & & & \\
$\quad$ Vaginal & & & \\
$\quad$ Cesarean section & $98.3 \%$ & $99.3 \%$ & 0.5 \\
Hypertension of pregnancy (\%) & $1.1 \%$ & $2 \%$ & 0.5 \\
Gestational diabetes mellitus (\%) & 0 & $0.6 \%$ & 0.5 \\
Birth weight (g) & 3040 & 2895.7 & 0.0001 \\
& \pm 315 & \pm 350 & $(\mathrm{~S})$ \\
\hline
\end{tabular}

Table 2 shows the average duration of the first stage of labor of patients who delivered male babies and patients who delivered female babies. There is no statistical 
significance between the duration of labor for both patients.

Table 2: Duration of first stage of labor (minutes)

\begin{tabular}{ccc}
\hline Males & Females & P value \\
$415.12 \pm 213$ & $416 \pm 200$ & $0.9697(\mathrm{NS})$ \\
\hline
\end{tabular}

Fig 1: Duration of labor between the women carrying male and female fetuses

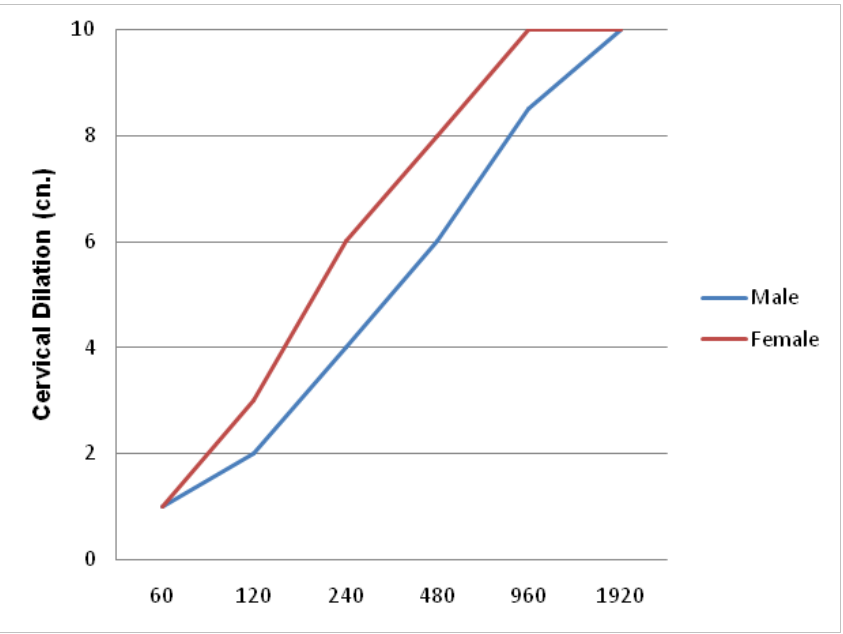

Women who carried a male fetus had a longer active first stage of labor than women who carried a female fetus (Fig 1).

Table 3: Comparison between the duration of labor (minutes)

\begin{tabular}{lccc}
\hline \multicolumn{1}{c}{ Labor } & Males & Females & P Value \\
\hline Induction & 391.2 & 306.7 & \\
& \pm 317 & \pm 155 & $0.5610(\mathrm{NS})$ \\
Augmentation & 437.4 & 434.6 & \\
& \pm 202.7 & \pm 198 & $0.9272(\mathrm{NS})$ \\
Spontaneous & 392.2 & 398.4 & $0.8665(\mathrm{NS})$ \\
& \pm 211.2 & \pm 230.3 & \\
\hline
\end{tabular}

Table 3 shows the labor duration difference when compared between genders and stratified by whether labor was induced, augmented or spontaneous. The analysis showed no significant difference between the duration of labor of women who carried a male fetus and women who carried a female fetus.

The parity of the patients was stratified and the length of labor was compared. It showed that there is no statistical difference between the duration of labor for nulliparous women who carried a male fetus and nulliparous women who carried a female fetus. On average, it was also seen that there is no statistical difference between multiparous women who carried a male fetus and multiparous women who carried a female fetus (Table 4).

Table 4: Comparison between the duration of labor and parity (minutes)

\begin{tabular}{cccc}
\hline \multicolumn{1}{c}{ Parity } & Males & Females & P Value \\
\hline Nulliparous & $460.7 \pm 240$ & $442 \pm 201$ & $0.5927(\mathrm{NS})$ \\
Multiparous & $374.8 \pm 178$ & $391 \pm 197$ & $0.5810(\mathrm{NS})$ \\
\hline
\end{tabular}

\section{DISCUSSION}

The association of fetal sex with pregnancy induced hypertension and pre-eclampsia, the interaction between sex and risk factors for fetal growth restriction, and the increased likelihood of second stage arrest with male sex have all been studied. However, there are only a few studies on the effect of fetal sex itself on labor duration. This study set out to determine the effect of fetal sex on duration of labor.

This research shows that among the pregnant women who delivered male babies, the average duration of labor was $415.12 \pm 213$ minutes as compared with pregnant women who delivered female babies with an average duration of labor of $416 \pm 200$ minutes.

This study also compared the duration of labor whether it was induced, augmented or spontaneous. Women who carried male fetuses had a slightly longer duration of induced labor (391.2 \pm 317 minutes) than women who carried female fetuses (306.7 \pm 155 minutes). The duration of labor in both women subjects are generally the same with regard to augmented or spontaneous labor.

The parity of the subjects was also considered in resolving the difference of labor duration. It was found that on average, there is no statistical difference in the labor duration of nulliparous women who delivered male fetuses and nulliparous women who delivered female fetuses. There was also no statistical difference between the duration of labor for multiparous women who delivered male fetuses and female fetuses.

Within a large, retrospective cohort study of consecutive, reported by Cahill AG et al showed an incidence of 2400 women, 2373 women had complete labor information and were available for this analysis. Male gender was associated with both a statistically significantly longer active first stage of labor (4.6 vs 4.0 hours; P.002) and stratified analyses by parity and labor type ${ }^{15}$. 


\section{CONCLUSIONS}

We found term labor in the first stage to be slower in women who carried a male fetus compared with those with female fetuses. This small, but statistically significant difference, in the duration of labor by fetal gender was seen when data were stratified by labor type and parity and when fetal size and other confounding factors were accounted for. Fetal gender, often known at the time of onset of labor, is one of many factors that might allow physicians to individualize the diagnosis of arrest in the first stage of labor and avoid unnecessary cesarean deliveries.

Other investigators have identified fetal gender as a risk factor for cesarean delivery. In a retrospective cohort study of $>90,000$ deliveries $^{16}$, found that women who carried a male fetus were at a $20 \%$ increased risk to be diagnosed with an arrest disorder and undergo cesarean delivery in the first stage of labor compared with women who carried a female fetus.

\section{REFERENCES}

1. Cunningham FG, Leveno KJ, Bloom SL, Hauth JC, Rouse DJ. Normal labor and delivery. Williams Obstetrics. 23 edition. Chapter 17: 384-386.

2. Cunningham FG, Leveno KJ, Bloom SL, Hauth JC, Rouse DJ. Parturition. Williams Obstetrics. 23 edition. Chapter 6: 141-142.

3. Sheiner E, Levy A, Feinstein U, Hallak M, Mazor M. Risk factors and outcome of failure to progress during the first stage of labor: A population-based study. Acta Obstet Gynecol Scand. 2002; 81: 222-6.

4. Feinstein U, Sheiner E, Levy A, Hallak M, Mazor M. Risk factors for arrest of descent during the second stage of labor. Int J Gynaecol Obstet. 2002; 77: 7-14.

5. Di Renzo GC, Rosati A, Sarti RD, Cruciani L, Cutuli AM. Does fetal sex affect pregnancy outcome? Gend Med. 2007; 4: 19-30.
6. Norwitz ER, Robinson JN, Challis JR. The control of labor. $N$ Engl J Med. 1999; 341: 660-6.

7. Khoury MJ, Marks JS, McCarthy BJ, Zaro SM. Factors affecting the sex differential in neonatal mortality: The role of respiratory distress syndrome. Am J Obstet Gynecol. 1985; 151: 777-782.

8. Verloove-Vanhorick SP, Veen S, Ens-Dokkum MH, Schreuder AM, Brand R, Ruys JH. Sex difference in disability and handicap at five years of age in children born at very short gestation. Pediatrics. 1994; 93: 576-579.

9. Smith, GC. Sex, birth weight, and the risk of stillbirth in Scotland, 1980-1996. Am J Epidemiol. 2000; 151: 614-619.

10. Stevenson DK, Verter J, Fanaroff AA, Oh W, Ehrenkranz RA, Shankaran S, Donovan EF, Wright LL, Lemons JA, Tyson JE et al. Sex differences in outcomes of very low birth weight infants: The newborn male disadvantage. Arch Dis Child. 2000; 83: F182-185.

11. Cooperstock M, Campbell J. Excess males in preterm birth: Interactions with gestational age, race, and multiple births. Obstet Gynecol. 1996; 88: 189-193.

12. Hall MH, Carr-Hill R. Impact of sex ratio on onset and management of labor. Br Med J. (Clin Res Ed). 1982; 285(6339): 401-403.

13. James $\mathbf{W H}$. Why are boys more likely to be preterm than girls? Plus other related conundrums in human reproduction. Hum Reprod. 2000; 15: 2108-2111.

14. Bernstein ME. Gestation length and sex of child. Hum Reprod. 1998; 13: 2975-2976.

15. Cahill AG, Roehl KA, Odibo AO et al. Impact of fetal gender on the labor curve. Am J Obstet Gynecol. 2012; 206: 335. e1-5.

16. Sheiner E, Levy A, Feinstein U, Hallak M, Mazor M. Risk factors and outcome of failure to progress during the first stage of labor: A population-based study. Acta Obstet Gynecol Scand. 2002; 81: 222-226. 